\title{
Online Persuasion for E-Commerce Websites
}

\author{
Muna M. Alhammad \\ University of Reading, Henley Business School \\ Whiteknights, Reading, UK \\ m.m.s.alhammad@pgr.reading.ac.uk
}

\author{
Stephen R. Gulliver \\ University of Reading, Henley Business School \\ Whiteknights, Reading, UK \\ s.r.gulliver@henley.reading.ac.uk
}

\begin{abstract}
The persuasive design of e-commerce websites has been shown to support people with online purchases. Therefore, it is important to understand how persuasive applications are used and assimilated into e-commerce website designs. This paper demonstrates how the PSD model's persuasive features could be used to build a bridge supporting the extraction and evaluation of persuasive features in such e-commerce websites; thus practically explaining how feature implementation can enhance website persuasiveness. To support a deeper understanding of persuasive e-commerce website design, this research, using the Persuasive Systems Design (PSD) model, identifies the distinct persuasive features currently assimilated in ten successful e-commerce websites. The results revealed extensive use of persuasive features; particularly features related to dialogue support, credibility support, and primary task support; thus highlighting weaknesses in the implementation of social support features. In conclusion we suggest possible ways for enhancing persuasive feature implementation via appropriate contextual examples and explanation.
\end{abstract}

\section{E-Commerce, Persuasive System Design, Persuasion Context, Design Principles.}

\section{INTRODUCTION}

Persuasive technologies are designed to attempt to change or shape a person's attitude and/or behaviour concerning an issue, object, or action without using coercion or deception (Fogg, 2003). Literature provides guidelines for designing and evaluating persuasive systems (e.g. Fogg (2003); Oinas-Kukkonen and Harjumaa (2009)), often placing explicit attention on understanding persuasive design strategies incorporated in the domain of health persuasive systems (e.g. Langrial et al. (2012); etc.). No research, however, currently investigates how specific persuasive features and functionalities should be assimilated within online commerce websites despite the common use of persuasive applications.

Kaptein and Duplinsky (2009) study the use of persuasive application in e-commerce, yet focus on adapting persuasive messages, i.e. the use of persuasion profiling in the context of e-commerce. Felfernig and Burke (2008) study attempts to expose reasons behind successful e-commerce websites; however, only a few persuasive features are described. A deeper understanding of the design of persuasive e-commerce website is needed. To achieve this, using the Persuasive
Systems Design (PSD) model (Oinas-Kukkonen and Harjumaa, 2009) as a theoretical foundation, this research aims to identify distinct persuasive features assimilated and employed in a set of successful e-commerce websites. The PSD model is the most comprehensive framework for developing and evaluating persuasive systems (Oinas-Kukkonen, 2013). The model helps to structure thinking and provides maps for selecting system features and requirements by analysing the persuasion context by addressing the intent (intended change), the event (use, users and the context), and the strategy (persuasive message and delivery route). Hence, this study answers the following question: what varieties of persuasive systems' features are employed in the most successful e-commerce websites?

\section{RELATED RESEARCH}

\subsection{Persuasive e-commerce design}

As online shopping becomes a routine way of shopping, the design and functionalities of websites play a significant role in differentiating e-commerce providers. The website is often the first contact point with consumers and contributes to shaping users impressions towards repeated use of the 
website (Everard and Galletta, 2006, Zhang et al., 2011); it is therefore essential that a favourable image is presented. High quality websites attract more users, and are able to convert 'browsers' into 'shoppers' (Högström et al., 2010). Currently, many persuasive features are extensively applied in the design of e-commerce websites to enhance their overall quality through emphasising website credibility and improving marketing strategies (Fogg et al., 2003, Kaptein and Duplinsky, 2009). E-commerce presents a perfect platform for persuasive tools, i.e. attracting users to visit the website, presenting products in the most attractive manner, attracting user attention to special sales and promotions, suggesting related products, and finally facilitating the purchase process (Winn and Beck, 2002). Designers of online shopping websites combine their knowledge of design, technology, and social science to design persuasive e-commerce websites that are ideally able to enhance consumers' satisfaction and ultimately increase retailers' revenues.

Winn and Beck (2002) study examines how different visual elements operate to persuade users, and facilitate more persuasive e-commerce design. However, due in part to changes in the capabilities of technology it is illogical to rely solely on this study. It is our belief that the persuasive design of e-commerce websites needs to be reexamined, using recent persuasive design frameworks i.e. the PSD model, due to the nature of e-commerce website design that have persuasive purposes.

\subsection{Persuasive systems design and evaluation}

Persuasion is defined as the communication process in which a persuader sends a persuasive message to the recipient (persuadee) with the intention of influencing attitude and/or behaviour, whilst leaving the recipient with the power of decision (Briñol and Petty, 2009). Persuasive Technologies are defined as any technologies designed to alter people's attitudes and/or behaviour (Fogg, 2003).

Several frameworks exist to support the design of persuasive systems. Lockton et al. (2010) introduced the 'Design with Intent' (Dwl) framework, which illustrates how to use design to modify behaviour, and how different persuasive techniques could be applied across domains. The Dwl toolkit classified ranges of persuasive design patterns into eight groups, based on eight different 'lenses'; where each lens could influence behaviour from a different perspective, e.g. cognitive, interactive, security, etc. (Lockton et al., 2010). Fogg (2009) behaviour model states that in order for individuals to be persuaded, three conditions should be met. These conditions are: users must be highly motivated, users must have the ability to perform the behaviour, and users must receive a trigger at the right time to perform the targeted behaviour (Fogg, 2009). Although Fogg's model does not clearly explain how persuasive features can be implemented in the design of persuasive systems, Fogg previously considered this in his functional triad framework (Fogg, 2003). This framework states that computers can play three major persuasive roles, which are: tool, media, and social actor. Each of these roles has a set of persuasive strategies that can be used to achieve persuasion.

The Persuasive Systems Design (PSD) model (Oinas-Kukkonen and Harjumaa, 2009) highlights seven postulates that should be understood by designers before analysing and designing persuasive systems. These postulates are deemed as fundamental to the design of any persuasive systems that allow us to see how we design persuasion strategies. The model emphasises the importance of analysing the persuasion context, i.e. the intent (the intended change in behaviours and/or attitudes), the event (analysing the use context, user context and the technology context) and the strategy (identifying the route that will promote persuasion). After analysing the persuasion context, designers should ensure that the system demonstrates a specific set of persuasive system features (non-functional requirements) that are categorised into four groups namely: primary task support (facilitating users' interaction with a system and helps track their performance), dialogue support (improving dialogue between the user and the system, especially in terms of system's feedback), credibility support (making the system design more credible), and social support (increasing user motivation through incorporating a range of social influence features).

\section{RESEARCH METHODOLOGY}

\subsection{Selected e-commerce websites}

We aimed to test a concise yet representational set of successful e-commerce portals. Ten websites were selected; five based on ranked popularity, and five on ranked sales conversion rates. The five most popular e-commerce websites, as sourced from the web service called Alexa, were (in order): Amazon, Ebay, Netflix, Walmart, and Ikea. The top conversion e-commerce websites, as defined by Nielson Company (Nicholls, 2010), were: Schwan's (41.7\%), ProFlowers (26.5\%), Vitacost (24.0\%), Woman Within (22.4\%), and Blair $(20.5 \%)$.

\subsection{Analysis method}

This paper aims to explore, identify and understand the design of successful e-commerce websites by 
classifying their persuasive features. It also represents a new opportunity to learn from practice and understand how different persuasive features have been implemented by many successful ecommerce websites and how such implementation could be enhanced. Expert evaluation was used where one or more specialists evaluate the website against a checklist of list of persuasive design features. The checklist, presented in Table 1, was based on the 28 persuasion features defined by the PSD model (Oinas-Kukkonen and Harjumaa, 2009). Expert empirical evaluation was used to walk through regular tasks within specific websites, with functionalities checked against given definitions in the checklist. One evaluator made notes on an Excel sheet and recorded relevant comments. The evaluator sought other expert's opinions regarding the evolution of functionalities that are not clear and might be related to more than one persuasive feature. When the evaluator concluded the evaluation, another expert reviewed the recorded notes and comments against the utilised checklist and rigorous discussion and iterations took place to ensure that notes and comments were recorded against the right persuasive feature.

\section{FINDINGS}

\subsection{The Persuasion context of e-commerce applications}

The first step, according to the PSD model, is to identify the intent, the event and the strategy of the selected websites, i.e. to formulate a persuasion context. As the analysed websites are not designed for behavioural change, it was hard to identify an explicit persuasion context for all websites. However, the following PSD context was highlighted:

The intent: the main persuaders are the online retailers, i.e. the operators of the interactive ecommerce websites. The intention of website developers is not clearly stated, yet is presumed to relate to commercial purposes, i.e. to sell more products/services to their users. In addition, one website (Vitacost.com) claimed to support users in adopting healthy behaviour by offering discounted products concerning healthy living.

The event: from the 'about us' page information, we identified that all websites are designed for people who wish to save time and/or effort, or enjoy the experience of shopping online. The WomanWithin website is dedicated to plus size women, allowing overweight women to easily find everything they need in one website. The Vitacost website targets users who are interested in healthy living products. All websites operate online, so users can shop at any time, from anywhere. The digital nature of the online shopping environment involves risks; hence, credibility requires more emphasis.

Table 1: Checklist for recognising persuasive features, adapted from Oinas-Kukkonen and Harjumaa (2009)

\begin{tabular}{|c|c|}
\hline $\begin{array}{l}\text { Persuasion } \\
\text { Principle } \\
\end{array}$ & Description and Characteristic \\
\hline Reduction & $\begin{array}{l}\text { Simplifies complex activities into easy } \\
\text { tasks e.g. buy with one-click only }\end{array}$ \\
\hline Tunnelling & $\begin{array}{l}\text { Guides users in the attitude change } \\
\text { process by bringing them closer to the } \\
\text { target behaviour e.g. Free trail signup. }\end{array}$ \\
\hline Tailoring & $\begin{array}{l}\text { Tailors information based on users } \\
\text { potential interests, usage context, or } \\
\text { other factors relevant to a user group. }\end{array}$ \\
\hline $\begin{array}{l}\text { Personalisa } \\
\text { tion }\end{array}$ & $\begin{array}{l}\text { Offers personalised content e.g. } \\
\text { personalised recommendation }\end{array}$ \\
\hline $\begin{array}{l}\text { Self- } \\
\text { Monitoring }\end{array}$ & $\begin{array}{l}\text { Allows the customers to keep track of } \\
\text { their performance or status e.g. order } \\
\text { tracking or review previous history. }\end{array}$ \\
\hline Simulations & $\begin{array}{l}\text { Provides means for observing the link } \\
\text { between the cause and the effect, e.g. } \\
\text { virtual fitting room. }\end{array}$ \\
\hline Rehearsal & $\begin{array}{l}\text { Provides means for rehearsing a target } \\
\text { behaviour, e.g. short video clarifying the } \\
\text { online buying process. }\end{array}$ \\
\hline Praise & $\begin{array}{l}\text { Uses words, images, or sounds to give } \\
\text { the user positive feedback }\end{array}$ \\
\hline Rewards & $\begin{array}{l}\text { Offers users some reward for } \\
\text { performing the target behaviour, e.g. } \\
\text { online discounts, vouchers, etc. }\end{array}$ \\
\hline Reminders & $\begin{array}{l}\text { Reminds the user about the target } \\
\text { behaviour during the use of the website } \\
\text { e.g. remainder email about sale event. }\end{array}$ \\
\hline Suggestion & $\begin{array}{l}\text { Suggests products or services at the } \\
\text { opportune moment. }\end{array}$ \\
\hline Similarity & $\begin{array}{l}\text { Website imitates its users by using their } \\
\text { language, date, and currency. }\end{array}$ \\
\hline Liking & $\begin{array}{l}\text { Website has a look and the feel that } \\
\text { appeals to its customers. }\end{array}$ \\
\hline Social Role & $\begin{array}{l}\text { Website adopts a role of social actor } \\
\text { e.g. embedded conversational agent } \\
\text { offering advice and assistance. }\end{array}$ \\
\hline $\begin{array}{l}\text { Trustworthi } \\
\text { ness }\end{array}$ & $\begin{array}{l}\text { Provides the customers with truthful, } \\
\text { fair and unbiased information, e.g. } \\
\text { website clearly states privacy, shipping } \\
\text { and returning policies. }\end{array}$ \\
\hline Expertise & $\begin{array}{l}\text { Offers information showing knowledge, } \\
\text { experience, and competence, e.g. } \\
\text { website regularly updated, no dangling } \\
\text { links or out of date information. }\end{array}$ \\
\hline $\begin{array}{l}\text { Surface } \\
\text { credibility }\end{array}$ & $\begin{array}{l}\text { Website has a competent look and feel, } \\
\text { e.g. the design reflects the context. }\end{array}$ \\
\hline $\begin{array}{l}\text { Real-world } \\
\text { feel }\end{array}$ & $\begin{array}{l}\text { Provides information about organisation } \\
\text { providing the services, e.g. provides } \\
\text { clear customer service contact details } \\
\text { like phone, post, or online chat. }\end{array}$ \\
\hline Authority & $\begin{array}{l}\text { Website refers to organisation or } \\
\text { people in the role of authority, e.g. } \\
\text { quoting authority statements from } \\
\text { authorised organisation or people. }\end{array}$ \\
\hline $\begin{array}{l}\text { Third-party } \\
\text { endorseme } \\
\text { nts }\end{array}$ & $\begin{array}{l}\text { Provides endorsements from respected } \\
\text { sources e.g. security certificate logos } \\
\text { from well-known security companies. }\end{array}$ \\
\hline
\end{tabular}




\begin{tabular}{|l|l|}
\hline Verifiability & $\begin{array}{l}\text { Provides means to verify the accuracy } \\
\text { of the website content via outside } \\
\text { sources. }\end{array}$ \\
\hline $\begin{array}{l}\text { Social } \\
\text { Learning }\end{array}$ & $\begin{array}{l}\text { Allows users to observe other } \\
\text { customers' behaviour and outcomes, } \\
\text { e.g. customer review board, showing } \\
\text { what other users are experiencing, etc. }\end{array}$ \\
\hline $\begin{array}{l}\text { Social } \\
\text { Comparison }\end{array}$ & $\begin{array}{l}\text { Allows customer to compare own } \\
\text { performance with other customers, e.g. } \\
\text { customer review board. }\end{array}$ \\
\hline $\begin{array}{l}\text { Normative } \\
\text { Influence }\end{array}$ & $\begin{array}{l}\text { Provides means for gathering together } \\
\text { customers who share the same goal or } \\
\text { leverage, normative influence or peer } \\
\text { pressure to increase the likelihood that } \\
\text { a person will adopt target behaviour. }\end{array}$ \\
\hline $\begin{array}{l}\text { Social } \\
\text { facilitation }\end{array}$ & $\begin{array}{l}\text { Allows users to discern other users } \\
\text { performing the same behaviour along } \\
\text { with them, e.g. what others watch and } \\
\text { buy right now. }\end{array}$ \\
\hline Cooperation & $\begin{array}{l}\text { Allows customers to cooperate, e.g. } \\
\text { customer review board. }\end{array}$ \\
\hline Competition & $\begin{array}{l}\text { Provides means of competing with } \\
\text { other customer, e.g. online auction. }\end{array}$ \\
\hline Recognition & $\begin{array}{l}\text { Provides public recognition for users } \\
\text { who perform their target behaviour, e.g. } \\
\text { name of awarded people are published } \\
\text { on the website. }\end{array}$ \\
\hline
\end{tabular}

The strategy: Designers identify the route and message that will promote persuasion. The routes may be direct (using logical argument), indirect (using cues) or a mix of both, depending on the user characteristics and ability to assess the meaning of persuasive messages. The analyses of the websites indicated compact presentation of messages, and both direct and indirect routes were used in almost all websites. As all e-commerce websites uses unobtrusive persuasive technologies, they neither state the persuasion intent nor the type of change being targeted. We assume they are targeting both change in behaviour and attitude, i.e. they aim to persuade the user to buy online and to be loyal to their website. Although some of the websites attempt to consider user background, all failed to include such differences in persuasive message and route types.

\subsection{Identified Persuasive Features}

The use of the PSD model assisted us in identifying precise persuasive features for system qualities that promote persuasive interactions. Results show that dialogue support (i.e. $85 \%$ feature coverage across the 10 sites) is the most common persuasive features with credibility support, primary task support, and social support gaining scores of $74 \%, 71 \%$, and $51 \%$ coverage respectively.

\subsubsection{Dialogue support}

Dialogue support features were the most highly utilised features, with all websites incorporating features that support dialogue between the user and online trader. $90 \%$ of the websites used praise, i.e. giving positive verbal feedback after registration or purchasing products/services from the website; e.g. 'Congratulations, you have successfully completed your order'. Also, all of the websites rewarded the users with online vouchers if they have performed particular actions, such as successfully inviting friends to buy from the website, or offering points for future purchase. This can help motivate users to i) purchase online and ii) be loyal to the online trader. Reminders were employed in different forms, such as emails regarding specific events. Additionally, websites regularly reminded users to check out when they have added products to the shopping basket, i.e. to ensure that users are reminded to perform the behaviour of purchasing from the website. Suggestions came in a form of recommender systems, i.e. where the website suggests other products that other users bought when buying a particular product or suggesting items that the user may like based on their previous search interest. Seven websites adopted a social role, i.e. automated online assistance, with one of them offering an online community centre where users can chat with each other to discuss related issues. Similarity was the least used dialogue support feature; with only half of the websites adapting this feature.

\subsubsection{Credibility support}

Credibility is commonly defined as believability (Fogg, 2003). Credibility has significant influence on persuasion and website persuasiveness (Fogg, 2003, Cugelman et al., 2009). Based on results, it appears that all websites have a high credibility. Trustworthiness, expertise, surface credibility and real-world feel have been implemented in all of the websites. Interestingly, the five top websites, i.e. in terms of conversion rate, do not have physical stores. Despite a pure online presence, all employ real-world features to increase their credibility by providing information about their organisations and their contact details with four of them providing online chat. Surface credibility, as opposed to earned credibility, is related to website look and feel. The influence of surface credibility is assumed to be useful in the initial stages of interaction, i.e. when earned credibility has not yet been established (Harjumaa et al., 2009). Users, for example, often link website appearance with website quality and credibility. Surface credibility was measured in relation with two particular aspects: i) the website should reflect the context, and ii) the website does not have an unreasonable number of advertisements on it. Expert evaluation concerning this feature showed that the top five websites, in terms of conversion, did not present any advertisements for other websites, i.e. they only presented their own products/services, avoiding passing customers over to other websites. It seems particularly important to keep the users on 
their websites, and to avoid distracting them from the main target behaviour. Third party endorsements were used in eight websites, i.e. where websites provide endorsements from respectable external sources, e.g. PayPal, McAfee SECURE TM Trustmark, etc. Authority, i.e. providing a means to verify the accuracy of the site content via external sources, were seldom employed; with only two websites employing these features i.e. Amazon and EBay where they verify the credibility of small sellers by allowing them to sell their products under the umbrella of Amazon or EBay.

\subsubsection{Primary Task Support}

The primary task is the main task or activity that the website is designed to support, i.e. support the user's primary task of purchasing online. The analysis indicated that all primary task features were utilized, with the exception of simulation and rehearsal features. Reduction, tunnelling, tailoring, and self-monitoring (see Table 1) appeared to be the most common features as they were employed by all selected websites. Personalisation was applied in $60 \%$ of websites, which offered personalised recommendations based on users' interests and search history.

\subsubsection{Social support}

Social support was the least common category utilised in the websites. Social support influences the persuasiveness of the website as users' attitude or behaviour is usually influenced by the attitude and behaviour of other people (OinasKukkonen and Harjumaa, 2009). When users see others using the same website, and when the website allows the users to compare their behaviour with the outcomes of others, user attitude is often influenced either positively or negatively. In this study, normative influence was the most common social support feature; adopted in 9 websites. Customers review boards and social media links are common implementation examples of this feature. Users were allowed to email items or share questions through social media to get others comments. Social learning, social comparison and cooperation were adapted in 8,7 and 7 websites respectively. These features are extremely important to improve user motivation to perform the target behaviour. Social facilitation was applied in $30 \%$ of the websites; increasing users' motivation and website persuasiveness by allowing users to discern the behaviour of other users who use the website at the same time i.e. 'what other users watch and buy right now'. Competition and recognition was only used by Ebay; an online marketplace website. This is due, in part, to the non-competitive nature of e-commerce business.

\section{DISCUSSIONS, CONCLUSION, AND FUTURE RESEARCH}

Findings imply that persuasive technology features are extensively used in successful e-commerce websites. The implementation and design of dialogue support was found to be highly harmonised with the nature of the digital environment; with extensive support needed for effective interaction between shoppers and online traders. A lack of positive interaction can lead to shoppers being reluctant to complete a financial transaction. Therefore, designers emphasis on dialogue support features to enhance the persuasiveness of the website. Credibility support is the second highest category and is key to directly and indirectly influencing users' purchase decisionmaking (Everard and Galletta, 2006) via persuasion (Angst and Agarwal, 2009). Hence, as e-commerce websites involve buyer risk, designers of successful e-commerce websites place a high emphasis on building credibility and trust. Credibility is influenced by website appearance, real-world feel, surface credibility, third-party endorsement, verifiability, and authority. Interestingly the top websites show limited utilisation of verifiability and authority. This is perhaps due to a lack of knowledge concerning the influence of verifiability and authority on credibility and persuasion. Such features could significantly build credibility; hence, persuasion. Primary task support, which was the third most employed category, aimed to enhance users selfefficacy (Webster and Ahuja, 2006). Websites attempted to support users during their shopping experience by reducing the effort required and bringing the users closer to the targeted behaviour to improve the persuasiveness of the website. Nevertheless, further utilisation of simulation is needed. Simulation has huge potential to enhance persuasion in the context of e-commerce. Although it is still uncommon in the e-commerce domain, some websites do apply it to enhance the overall customer experience. For example, ProFlowers have demonstrated how this feature can be implemented effectively when matching flowers to vases. It uses image manipulation to allow the users to see the final look of the flowers when combined with different vases, allowing the user to observe the link between the cause and effect. The use of social support was found to be relatively limited. Hendler et al. (2008) stated that the success or failure of a website seems to rely mostly on social features. Hence, a better understanding of the social support features and functionalities and the way they influence people, is essential. In this study, Ebay and Amazon were the websites with high utilisation of social support features; with almost all features implemented within Ebay. Although this may justify their ranking for being the highest visited e-commerce websites, additional study is recommended to investigate such hypotheses. Recognition and competition were rarely utilised due to the nature of these features. These features do not align with the nature of e- 
commerce, except in limited cases, e.g. online auctions and market places (e.g. Ebay). Though incorporating such features and functionalities into the design of e-commerce website could increase its persuasiveness (Harjumaa et al., 2009), it should be noted that the quantity of persuasive features in each website does not determine the overall persuasiveness of the website (Langrial et al., 2012). Therefore, additional study is required to define if a link exists to user's perceptions of the overall persuasiveness of the website.

As we know now how different persuasive features are assimilated and implemented in the context of e-commerce, the next step in this research domain is to investigate user's preferences and responses to the reviewed persuasive features; i.e. which of these persuasive features actually contribute to user's perceptions of website persuasiveness. We proposed using features definitions and examples presented in Table 1 as a base for measuring each feature to help identify customer needs and preferences of the designed interactive ecommerce website. We are proposing there is a need to investigate the influence of individuals' culture on user's preferences of particular persuasive features. The findings from such research will allow us to develop guidelines to support those designing persuasive e-commerce for particular national or cultural segments.

\section{REFERENCES}

Angst, C. M. \& Agarwal, R. 2009. Adoption of electronic health records in the presence of privacy concerns: The elaboration likelihood model and individual persuasion. Management Information Systems Quarterly, 33, 339-370.

Briñol, P. \& Petty, R. E. 2009. Persuasion: Insights from the self validation hypothesis. Advances in experimental social psychology, 41, 69-118.

Cugelman, B., Thelwall, M. \& Dawes, P. 2009. Communication-Based Influence Components Model. Persuasive 2009. Claremont: ACM.

Everard, A. \& Galletta, D. F. 2006. How presentation flaws affect perceived site quality, trust, and intention to purchase from an online store. Journal of Management Information Systems, 22, 56-95.

Felfernig, A. \& Burke, R. Constraint-based recommender systems: technologies and research issues. Proceedings of the 10th international conference on Electronic commerce, 2008. ACM, 3.

Fogg, B., Soohoo, C., Danielson, D. R., Marable, L., Stanford, J. \& Tauber, E. R. How do users evaluate the credibility of Web sites?: a study with over 2,500 participants. Designing for user experiences, June 06-07 2003 San Francisco, California ACM, 1-15.
Fogg, B. J. 2003. Persuasive Technology: Using Computers to Change What We Think and Do, San Francisco, Morgan Kaufmann.

Fogg, B. J. A behavior model for persuasive design. the 4th International Conference on Persuasive Technology, 2009 Claremont, California, USA ACM, 40.

Harjumaa, M., Segerståhl, K. \& Oinas-Kukkonen, H. 2009. Understanding Persuasive Software Functionality in Practice: A Field Trial of Polar FT60. Persuasive Technology. California, USA: Springer.

Hendler, J., Shadbolt, N., Hall, W., Berners-Lee, T. \& Weitzner, D. 2008. Web science: an interdisciplinary approach to understanding the web. Communications of The ACM, 51, 60-69.

Högström, C., Rosner, M. \& Gustafsson, A. 2010. How to create attractive and unique customer experiences: an application of Kano's theory of attractive quality to recreational tourism. Marketing Intelligence \& Planning, 28, 385-402.

Kaptein, M. \& Duplinsky, S. 2009. Combining Multiple Influence Strategies to Increase Consumer Compliance.

Langrial, S., Lehto, T., Oinas-Kukkonen, H., Harjumaa, M. \& Karppinen, P. 2012. Native Mobile Applications For Personal Well-Being: A Persuasive Systems Design Evaluation. The Pacific Asia Conference on Information Systems. Vietnam: Association of Information Systems.

Lockton, D., Harrison, D. \& Stanton, N. A. 2010. The Design with Intent Method: A design tool for influencing user behaviour. Appl Ergon, 41, 382392.

Nicholls, C. 2010. Lessons Learned from the top 10 Converting Websites. Andover, USA: Conversion Academy.

Oinas-Kukkonen, H. 2013. A foundation for the study of behavior change support systems. Personal and Ubiquitous Computing, 17, 12231235.

Oinas-Kukkonen, H. \& Harjumaa, M. 2009. Persuasive systems design: Key issues, process model, and system features. Communications of the Association for Information Systems, 24.

Webster, J. \& Ahuja, J. S. 2006. Enhancing the design of web navigation systems: the influence of user disorientation on engagement and performance. Management Information Systems Quarterly, 30, 661-678.

Winn, W. \& Beck, K. 2002. The persuasive power of design elements on an e-commerce web site. Technical Communication, 49, 17-35.

Zhang, Y., Fang, Y., Wei, K.-K., Ramsey, E., Mccole, P. \& Chen, H. 2011. Repurchase intention in B2C e-commerce-A relationship quality perspective. Information \& Management, $48,192-200$. 